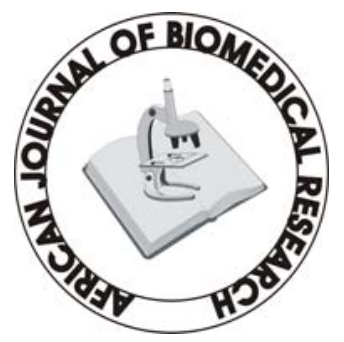

Full-text available at http://www.ajbrui.com \&

http://www.bioline.br/md

Received:

November, 2005

Accepted (Revised):

November, 2005

Published

January, 2006
Full Length Research Article

\section{The Importance of $\mathbf{O}$ - Level Grades in Medical School Admission: The University of Ado-Ekiti Experience}

\author{
D. D. O. Oyebola* \\ College of Medicine, University of Ado - Ekiti, \\ Ado - Ekiti, Nigeria
}

\section{ABSTRACT}

This paper describes the procedures used in the admission of the first set of Medical Students into the newly established College of Medicine, University of Ado - Ekiti. Two groups of students were admitted, namely, those admitted on the basis of their JAMB scores alone (five students) and those admitted on the basis of a combination of JAMB scores and O' level grades in Physics, Chemistry, Biology and Mathematics. In the latter group, the JAMB scores and $O$ ' level grades were given equal weighting (50\% of mark obtainable each) and all applicants were ranked on the basis of their combined scores. The 127 top scorers based on this ranking were given a written interview test and an oral interview. At the end of the exercise, 40 candidates were admitted. Eventually, 31 of this group and four out of the five candidates admitted with JAMB scores alone registered for 100 Level courses. A comparison of the academic performance of the two groups of students in science and General Studies courses at 100 Level showed that all students in the JAMB and O' level group were far better than students in the JAMB alone group. Indeed, the former group had outstanding performance while $50 \%$ of the latter group could not cope. It was concluded that the use of $O$ ' level grades is very important and effective in selecting academically sound students and should be used in admissions into Medical School. (Afr. J. Biomed. Res. 9: 15 - 21, January 2006)

Keywords: JAMB, O’ level grades, Medical school, Admission, Interview, Academic achievement, Ado-Ekiti

**Present/Correspondence address: Professor D. D. O. Oyebola, Department of Physiology, College of Medicine, University of Ibadan, Ibadan, Nigeria. E-mail: ddooyebola@yahoo.com 


\section{INTRODUCTION}

A major criterion for admission into all institutions of higher learning is academic excellence and the potential for same. All government-owned Universities in Nigeria admit candidates on the basis of their performance in the University Matriculation Examination (UME) conducted by the Joint Admissions and Matriculation Board (JAMB). Experience in many Universities in Nigeria has shown that the performance of students admitted into the universities in many cases do not correlate with their UME or JAMB scores. Studies conducted independently by Oyebola et al. (2000) and Bamgboye et al. (2001) showed clearly that there was no correlation between students' admission grades in JAMB and their performance in the University of Ibadan Medical School. Both studies showed that the Senior School Certificate Examination (SSCE) scores are a better predictor of performance at pre-clinical and 100 level examinations respectively than the JAMB scores. Both studies also recommended that the quality of the SSCE scores (or its equivalent) should be given high weighting during admission into the Medical School.

A recent study in the Faculty of the Social Sciences, University of Ibadan, which was cited by Kale in the year 2004 University Lecture (Kale 2004) provided interesting evidence in support of the lack of correlation between JAMB scores and academic achievement in the University. The study showed that the best performances in all the departments in the Faculty at the first year University Examinations were recorded by those students with JAMB scores of 221 to 240 or lower. Of particular interest is the Department of Geography, where the student with the best 100 level results was admitted with a JAMB score of 201 (Kale, 2004). In the same study, one student who came in with a JAMB score of above 270 did not pass the minimum five courses needed to stay on in the University and was therefore made to withdraw (Kale, 2004).

In October, 2001, the College of Medicine, University of Ado - Ekiti was established. Due to an unforeseen circumstance, the medical school had to use two procedures for the admission of the first set of medical students. A part of the set was admitted with their JAMB scores only while the second part was admitted using a combination of their JAMB scores and O' level grades in Mathematics, Chemistry, Physics and Biology (MCPB) plus an interview test.

The aim of this paper is to describe the procedure used for combining JAMB scores with O' level grades in $\mathrm{MCPB}$ and all the other steps taken for the purpose of admission of the first set of medical students into the
University of Ado-Ekiti. The study also aims at presenting a summary of the 100 level results of this first set of medical students in Physics, Chemistry, Zoology, Computer Science and General Studies courses so that their overall academic achievement can be assessed. Finally, the study aims at comparing the academic achievements at the 100 level examinations of the students admitted with JAMB and O' level scores combined with those of the students in the same set who were admitted with JAMB scores alone so as to assess whether there is a difference in the academic performance of the students admitted via these two processes. The comparison is with a view of providing answer to the question of whether the use of the quality of $\mathrm{O}^{\prime}$ level grades as criterion for admission or not using the $O^{\prime}$ level grades in deciding who gets admitted has any effect on the academic achievement of medical students.

\section{MATERIALS AND METHODS.}

Due to late entry into the year 2002 JAMB examination and other logistic problems, the College of Medicine, University of Ado-Ekiti (UNAD) had only four applicants on her first choice printout and seven applicants on her second choice print-out list from JAMB. Out of these, five candidates were admitted at the first admission exercise, three from the first choice list and two from the second choice list. This first batch is the JAMB score only group of the students admitted. Since this number was far lower than the quota of forty students the College planned to admit, an advertisement was placed in the newspapers that students who had applied for medicine in other medical schools who have not been offered admission should apply to UNAD for consideration. Those who could apply should not have scored less than 225 in the year 2002 JAMB examination and should send their O' level results with their JAMB result slips.

At the close of receiving applications, 630 candidates had applied. Assessment of the applicants was carried out as follows. Out of the maximum of 100 marks obtainable, JAMB scores carried 50 marks and the remaining 50 marks was for O' level grades in MCPB. That is, JAMB and O' level grades carried $50 \%$ each. Since the maximum score obtainable in JAMB examination is 400 , the JAMB score of each candidate was divided by eight to convert it to its equivalent over a maximum of 50 marks allotted to JAMB score. The divisor "eight" was obtained by dividing 400 by 50 . For the O' level grades, points were given to each grade such that A1 is 6 points, $\mathrm{A} 2$ (or B2) is 5 points, A3 (or B3) is 4 points, C4 is 3 points, C5 is 2 points and C6 is 1 point. On this scale, a candidate with four A1s in MCPB scores 24 points. To convert this 
to a score over 50 marks maximum score, the points scored were multiplied by two (2). Thus, the candidate with four A1s now scores 48 marks (i.e. $24 \times 2$ ). On this scale, a candidate with four A2s will score 40 points (i.e. $5 \mathrm{x} 4 \mathrm{x} 2$ ) etc. Candidates who score more than four As overall earned bonus marks as follows: 5As; plus half $(+1 / 2)$; 6 As plus one $(+1)$; 7As, plus one and a half $\left(+1 \frac{1}{2}\right)$ and 8As, plus two $(+2)$. Thus, a candidate with four A1s and a total of eight As scores $48+2$, which is 50 marks ( i.e. maximum score). The scores in the two areas (JAMB \& O' level) were then added together to obtain the final score percent. The candidates were then arranged in descending order based on their scores.

At the end of this computation, 127 candidates who scored 59\% and above were invited for interview. The interview consisted of written examinations in Physics, Chemistry, Biology and English, using the same format as that used in JAMB examinations. Adequate precautions were taken to prevent impersonation at the interview test. The written test was followed with an oral interview of all the candidates. The earlier assessment in JAMB and $\mathrm{O}$ ' level grades and those of the interview test were placed side by side for each candidate. In most cases, the order of merit was maintained in the two results. It is on the basis of these two sets of marks that the final admission was made, observing the usual criteria of merit, catchment area etc.

Out of the 40 students offered admission, 31 eventually registered for 100 level courses. Four of these
31 were from the first batch of JAMB score only admission (Group I) and the remaining 27 were those admitted using the combination of JAMB score and $\mathrm{O}^{\prime}$ level grades as well as interview test (Group II). At the end of each semester, the results of the100 level courses of these students were sent to the College from the various departments. At the end of the session, the results of all courses in chemistry, physics, zoology, computer science and General studies of these pioneer medical students were analysed so as to know how well the students have performed and the summary of these are presented under the results. Finally, the academic performance of students admitted as group I was compared with those admitted as group II to find out if one group was better academically than the other group.

\section{RESULTS}

Some of the results of this study are shown in Tables 1 to 4 . Table 1 shows extracts from the results of computation of JAMB and O' level scores as described above. Details such as names, JAMB registration numbers, States of origin and sex of applicants which were in the actual table used have been omitted in Table 1 so as to protect the identity of the applicants. The performance of the students in the interview test was similar in distribution to their assessment based on JAMB and O’ level scores.

TABLE I: Extract From Computed Score Sheet of Applicants Using Jamb and O’ Level Results

\begin{tabular}{|c|c|c|c|c|c|c|c|c|c|c|c|}
\hline \multirow[t]{2}{*}{$\mathrm{S} / \mathrm{N}$} & \multirow{2}{*}{$\begin{array}{l}\text { Jamb } \\
\text { Score }\end{array}$} & \multirow{2}{*}{$\begin{array}{c}\text { (A) } \\
\text { Jamb } \\
\text { Score } \\
\text { Over } 50\end{array}$} & \multicolumn{6}{|c|}{ O - Level Subjects } & \multirow{2}{*}{$\begin{array}{l}\text { O’ Level } \\
\text { Bonus } \\
\text { (Over } \\
\text { Max. Of } \\
2 \text { Marks }\end{array}$} & \multirow{2}{*}{$\begin{array}{l}\text { (B) } \\
\text { O' Level } \\
\text { Score } \\
\text { Over } 50\end{array}$} & \multirow{2}{*}{$\begin{array}{l}\text { Final } \\
\text { Score } \\
(\mathbf{A}+\mathbf{B}) \\
(\%)\end{array}$} \\
\hline & & & Phy & Chem & Bio & Maths & $\begin{array}{l}\text { Score } \\
\text { (Points) }\end{array}$ & $\begin{array}{l}\text { SCORE } \\
\text { OVER } \\
48\end{array}$ & & & \\
\hline 1 & 272 & 34.0 & A1 & A1 & A1 & A1 & 24 & 48 & +2 & 50 & 84 \\
\hline 2 & 260 & 32.5 & A1 & B2 & B2 & A1 & 22 & 44 & +2 & 46 & 78.5 \\
\hline 3 & 263 & 32.8 & A1 & A1 & B2 & B2 & 22 & 44 & $+1 \frac{1}{2}$ & 45.5 & 78.3 \\
\hline 4 & 255 & 31.8 & A1 & A1 & B2 & B2 & 22 & 44 & +1 & 45 & 76.8 \\
\hline 5 & 251 & 31.3 & A1 & C4 & A1 & B2 & 20 & 40 & $+1 / 2$ & 41 & 72.3 \\
\hline 6 & 233 & 29.1 & A1 & A1 & A1 & C4 & 21 & 42 & $+1 / 2$ & 42.5 & 71.6 \\
\hline 7 & 261 & 32.6 & B3 & B3 & B3 & B2 & 17 & 34 & - & 34 & 66.6 \\
\hline 8 & 285 & 35.8 & B3 & C5 & B3 & B3 & 14 & 28 & - & 28 & 63.6 \\
\hline 9 & 267 & 33.3 & B3 & B3 & B3 & C5 & 13 & 26 & - & 26 & 59.3 \\
\hline 10 & 229 & 28.6 & B3 & C4 & C4 & B3 & 14 & 28 & - & 28 & 56.6 \\
\hline 11 & 228 & 28.5 & C4 & C4 & C5 & B3 & 12 & 24 & - & 24 & 52.5 \\
\hline 12 & 227 & 28.3 & C5 & C4 & C6 & C5 & 08 & 16 & - & 16 & 44.3 \\
\hline
\end{tabular}

Note: Personal details of the candidates such as names, registration number, sex etc are not included in this Table so as to protect the rights of the candidates to privacy. 


\begin{tabular}{|c|c|c|c|c|c|c|c|c|c|c|c|c|}
\hline & & & - & ' LEVEI & JJE & $S \longrightarrow$ & & & & & & \\
\hline S/N & $\begin{array}{c}\text { JAMB } \\
\text { SCORE }\end{array}$ & $\begin{array}{c}\text { (A) } \\
\text { JAMB } \\
\text { SCORE* } \\
\text { OVER } 50\end{array}$ & PHY & CHEM & BIO & MATHS & $\begin{array}{l}\text { O’ LEVEL } \\
\text { SCORE* } \\
\text { (POINTS) }\end{array}$ & $\begin{array}{l}\text { O’ LEVEL } \\
\text { SCORE* } \\
\text { OVER } 48\end{array}$ & $\begin{array}{l}\text { O’LEVEL } \\
\text { BONUS } \\
\text { SCORE }\end{array}$ & $\begin{array}{c}\text { (B) } \\
\text { O' LEVEL SCORE } \\
\text { OVER } 50\end{array}$ & $\begin{array}{c}\text { FINAL } \\
\text { SCORE * } \\
(\mathbf{A}+\mathbf{B}) \\
\%\end{array}$ & REMARKS \\
\hline 1 & 245 & 30.6 & $\mathrm{C} 5$ & $\mathrm{C5}$ & $\mathrm{C} 5$ & C6 & 7 & 14 & - & 14 & 44.6 & 2 sittings \\
\hline 2 & 229 & 28.6 & C5 & C5 & C5 & B3 & 10 & 20 & - & 20 & 48.6 & 1 sitting \\
\hline 3 & 244 & 30.5 & C5 & C5 & $\mathrm{C} 4$ & C6 & 8 & 16 & - & 16 & 46.5 & 2 sittings \\
\hline 4 & 233 & 29.1 & C5 & C6 & $\mathrm{C} 5$ & C6 & 6 & 12 & - & 12 & 41.1 & 2 sittings \\
\hline
\end{tabular}

Asterisk (*) shows what the candidates would have scored if their O' level grades were used.

Table 3: Scores of the 1001 Medical Students in Some Courses

COURSES

\begin{tabular}{|c|c|c|c|c|c|c|c|c|c|c|c|}
\hline GRADES & PHY 101 & PHY 103 & CHM 101 & ZOO 101 & PHY 102 & CHM 102 & ZOO 102 & GST 101 & GST 105 & CSC 101 & $\begin{array}{c}\text { CUMULATIVE } \\
\text { GRADES }\end{array}$ \\
\hline A & 23 & 1 & 10 & 10 & 2 & 3 & 23 & 24 & 20 & 20 & $135(7)$ \\
\hline B & 4 & 8 & 15 & 15 & 14 & 11 & 2 & 6 & 10 & 10 & 74 \\
\hline $\mathrm{C}$ & 2 & 8 & 4 & 4 & 12 & 11 & 2 & 1 & 1 & - & 34 \\
\hline $\mathrm{D}$ & - & 3 & - & - & - & 1 & - & - & - & 1 & 4 \\
\hline E & 1 & 6 & - & - & 1 & 1 & 1 & - & - & - & 9 \\
\hline $\mathrm{F}$ & $1(1)$ & $5(3)$ & $2(2)$ & $2(2)$ & $1(1)$ & $3(3)$ & $2(2)$ & - & - & - & $16(14)$ \\
\hline Total (n) & 31 & 31 & 31 & 31 & $30 *$ & $30 *$ & $30 *$ & 31 & 31 & 31 & \\
\hline
\end{tabular}

(i) Course Code: PHY, Physics; CHM, Chemistry; ZOO, Zoology; GST, General Studies; CSC, Computer Science.

(ii) Note: A is 70\% and above, B $60-69$, C 50 - 59, D 45-49, E $40-44$ and F below 40 . Figures in parenthesis under F show number of candidates admitted with JAMB only who scored $\mathrm{F}$.

(iii) *One student withdrew voluntarily, in the second semester leaving a total of 30 students. 
Table 2 shows the O' level grades and JAMB scores of the four applicants admitted with JAMB scores only who actually registered at 100 level. It should be noted that the $\mathrm{O}$ ' level grades of these four applicants were not known until they came into the medical school and started registration. It should also be noted that three of the four applicants (75\%) achieved their O' level grades at two sittings. Also, none of them scored an A in Physics, Chemistry or Biology. What they would have scored if their JAMB and $\mathrm{O}$ ' level grades were combined as for the other applicants are also shown. It should be further noted that none of them scored 59\% which was the cut off mark used to determine the candidates to be invited for interview.

Table 3 summarizes the performance of the pioneer medical students in their 100 level examinations in the courses indicated. The grades of the candidates have been categorized into A, B, C, D, E and F. It should be noted that it is the candidates admitted with JAMB results only that scored 14 out of the total of 16 Fs in Table 3. Out of the total of 135 As scored, only 7 As were scored by the JAMB only group, while the remaining128As were scored by JAMB and O' level group, giving group "A" averages of 1.75 and 4.7 respectively $(n=4 ; n=27)$. The difference in the group " $A$ " average is highly significant $(\mathrm{P}<0.05 ; \mathrm{t}-$ test for unequal sample Means). All the students admitted with JAMB and O' level grades passed their 100 level courses and were allowed to proceed to 200 level. Only two of the four candidates (i.e 50\%) admitted with JAMB score only qualified to proceed to 200 level. The remaining two were asked to withdraw from the medical school.

Table 4 shows the raw scores of the four candidates admitted with JAMB results only in the 100 level courses. It should be noted that the serial number of the candidates in Table 2 correspond with the serial numbers of those in Table 4. Candidates numbers 1 and 4 in Table 4 had very poor grades, and the two of them were asked to withdraw from the programme at the end of the session. It should be noted that the two candidates asked to withdraw had lower O' level scores than the other two who passed (Table 2) even though one of them (S/N 1) had the highest
JAMB score of 245 in this group. The candidate with $\mathrm{S} / \mathrm{N} 2$ had the best grade in the group.

\section{DISCUSSION}

The processes of admission described above were carried out primarily to ensure that capable students were admitted as the foundation set of the new medical school at Ado-Ekiti. It was very important to go through these processes since the medical school was trying to admit some of the "rejects" of other medical schools. The initial aim was not to produce an academic paper. Therefore, neither the students involved in this study nor the lecturers who taught the courses whose results were used in the study were at any time aware that the study being reported here would be undertaken. Indeed, even the author of this work did not contemplate undertaking the study being reported here until the end of the session when the results of all the courses taken by the Medical Students at 100 level were received and an obvious difference was observed in the performance of the medical students admitted with JAMB results only and those admitted with JAMB and O' level results. Apart from the need to document this observation, it is believed that other institutions may find this experience useful. Hence, this paper was written. All the courses whose results are used in the study were taught and examined in the Faculty of Science and the General Studies Programme. This writer does not belong to or teach in that Faculty/Programme. The study is therefore free from bias.

The procedure used in computing the scores based on JAMB results and O' level grades have been described in detail so that any tertiary institution interested in using this method for admission of fresh students can easily adopt it, with or without modification. Although the present computation was done using a calculator, an appropriate computer software can do the job. The procedure for the conversion of the JAMB scores was devised by the author and it was based on the mathematical concept of scaling down the maximum score of JAMB which is 400 to a maximum of 50 .

TABLE 4

Raw Scores (\%) of the Four Candidates Admitted With Jamb Scores Only In Some Courses

\begin{tabular}{|c|c|c|c|c|c|c|c|c|c|c|c|}
\hline S/N & $\begin{array}{c}\text { JAMB } \\
\text { SCORE }\end{array}$ & $\begin{array}{c}\text { PHY } \\
\mathbf{1 0 1}\end{array}$ & $\begin{array}{c}\text { PHY } \\
\mathbf{1 0 3}\end{array}$ & $\begin{array}{c}\text { CHM } \\
\mathbf{1 0 1}\end{array}$ & $\begin{array}{c}\text { ZOO } \\
\mathbf{1 0 1}\end{array}$ & $\begin{array}{c}\text { PHY } \\
\mathbf{1 0 2}\end{array}$ & $\begin{array}{c}\text { CHM } \\
\mathbf{1 0 2}\end{array}$ & $\begin{array}{c}\text { ZOO } \\
\mathbf{1 0 2}\end{array}$ & $\begin{array}{c}\text { GST } \\
\mathbf{1 0 1}\end{array}$ & $\begin{array}{c}\text { GST } \\
\mathbf{1 0 5}\end{array}$ & $\begin{array}{c}\text { CSC } \\
\mathbf{1 0 1}\end{array}$ \\
\hline 1 & 245 & 43 & 30 & 18 & 22 & 34 & 35 & 18 & 64 & 66 & 49 \\
2 & 229 & 69 & 62 & 77 & 67 & 60 & 58 & 80 & 78 & 65 & 78 \\
3 & 244 & 66 & 30 & 60 & 54 & 62 & 37 & 70 & 68 & 73 & 69 \\
4 & 233 & 36 & 26 & 31 & 37 & 40 & 38 & 30 & 57 & 74 & 67 \\
\hline
\end{tabular}

Note the very poor performance of $\mathrm{S} / \mathrm{N} 1$ and 4 . Course codes are the same as in Table 3. 
This was achieved by using a divisor of 8 for the actual JAMB scores (i.e. 400 divided by 50, which is 8). This is the first time, as far as the author is aware, that this type of conversion will be applied to JAMB scores. The mathematical basis of the conversion is however simple and foolproof. It can therefore be used by others interested in similar studies with or without modification. Scoring O' level grades from 6 to 1 for A1 to C6 is well known in educational circles. Sometimes, this scoring is done in reverse order, especially in calculation of students' "aggregates" in the $\mathrm{O}$ ' level examination. In the latter, A1 is scored as 1 and C6 as 6. As far as the author is aware, this is the first time $\mathrm{O}$ ' level grades will be used in deciding admission into a Government-owned Nigerian University since the University Matriculation Examination (UME) conducted by JAMB was introduced in 1978. It is true candidates are often required to have at least credit passes in five prescribed subjects before they are admitted into the University, but the quality of the $\mathrm{O}$ ' level grades is never reckoned with in the actual admission process. As far as this requirement is concerned, a C6 is as good as an A1!

All the applicants who responded to the advertisement placed in the newspaper were people who did not obtain the cut-off marks in the various medical schools they had initially applied to. This was in spite of their outstanding $O$ ' level grades as shown in some of the samples in Table 1. Unfortunately, O’ level results were never taken into consideration at the point of deciding who to admit by most medical schools. It is for the latter reason, apart from shortage of candidates on our first JAMB printout, that candidates with the appauling $\mathrm{O}$ ' level results shown in Table 2 were admitted in our first admission exercise. These candidates would not have qualified to be invited for the interview test if they were to be considered on the basis of combined JAMB and O' level scores because none of them scored 59\%, which was the cut-off mark for interviewed candidates. In addition, three of them combined two results. Candidates with two $\mathrm{O}$ ' level results were not considered for admission in the group of the students admitted with JAMB scores and O' level grades (group II).

Since the results of the interview test followed the same distribution as the scores derived from the JAMB and $\mathrm{O}$ ' level scores, it is reasonable to conclude that in future admission exercises, not conducting an interview test will most probably not affect the quality of students admitted. This is provided none of the two results (JAMB and O' level) have been falsified, especially the $\mathrm{O}$ ' level results which can only be verified after admission. However, when candidates become aware that O' level grades are as important as JAMB scores for the purposes of admission, it is not unlikely that the incidence of $\mathrm{O}$ ' level result falsification will increase. Should this situation arise, interview tests should become mandatory so as to exclude cheats from getting admitted. If a test becomes necessary, any candidate whose interview test performance falls far below the earlier assessment based on JAMB and O' level scores should be dropped from the admission list.

The results shown in Tables 3 show that medical students admitted with JAMB and O' level grades had outstanding academic achievements in the University. Except in three courses (PHY 102, PHY 103 and CHM 102), roughly $70 \%$ of this group of students passed with " $A$ " grades in all the other courses (Table 3 ). Table 3 also shows that the four medical students admitted with JAMB scores alone accounted for 14 out of the total of 16 Fs scored in all subjects. Table 4 confirms the generally poor performance by two (50\%) of the latter group of students. At the end of session, not only did all the students admitted with JAMB and $\mathrm{O}$ ' level grades pass and were qualified to proceed to 200 Level, they passed most of their courses in A and B grades. In contrast, two of the four JAMB alone students (50\%) were so poor that they were required to withdraw from the programme. While it may be argued that the number of students involved in the JAMB only group is rather small as a control group, when one considers the overwhelmingly poorer performance of the group and that the best academic achiever among this group is the student who had the least JAMB score in the group but the best $\mathrm{O}$ ' level grades among them and these at one sitting, it is difficult to escape the conclusion that JAMB score alone is not a good criterion of choosing students who can cope well in the medical school. This finding concurs with an earlier report that there is no correlation between JAMB scores and students' performance in the medical school (Oyebola et al, 2000; Bamgboye et al. 2001) and indeed, in other courses too in the University (Kale, 2004). On the other hand, the mostly excellent results in Table 3 show that $\mathrm{O}$ ' level results in Physics, Chemistry. Biology and Mathematics (which were the subjects used in the admission of most of the medical students) are very good predictors of satisfactory academic achievement in the medical school.

In conclusion, this study reports for the first time the procedure of combining $\mathrm{O}$ ' level scores in MCPB and JAMB scores for assessing suitability of applicants for admission into a Medical School. A comparison of the performance in the 100 level examinations of the students admitted with JAMB scores only with those admitted with JAMB scores and O' level grades combined showed that students in group II had better academic achievements than those in group I. This shows that apart from JAMB scores, including the quality of $\mathrm{O}$ ' level grades at the admission stage in deciding who should be admitted ensures that students who can cope academically are those that get admitted. It is therefore recommended that $\mathrm{O}^{\prime}$ 
level grades should be used with JAMB scores for deciding admission into Medical Schools in Nigeria.

\section{Postscript:}

This paper was first presented at the $24^{\text {th }}$ Annual Scientific Conference of the Physiological Society of Nigeria at Delta State University, Abraka on $16^{\text {th }}$ September, 2004. Just about the time the full paper is submitted for publication, the Federal Government of Nigeria approved that Nigerian Universities can now screen UME applicants before admission.

\section{Acknowledgement}

I am grateful to Professors J. B. Olomo, H. A. Fagbami, Dr A. A. Fasanmade, Dr A. R. A. Alada and Mrs B. A. Oloketuyi for their assistance with the written and oral interview tests. I thank Mr. B. O. Awe for the manual computation of the JAMB scores and $O$ ' level grades for all applicants. I acknowledge, with thanks, all the lecturers who taught the 100 level courses to these pioneer medical students. Professor Victor Yoloye deserves special thanks. He designed the Zoology courses for the medical students and gave me a lot of encouragement. I also thank, Prof. Akin Oyebode, the Vice-Chancellor who persuaded me to take up the challenging task of being a Pioneer Provost at Ado-Ekiti for his support.

\section{REFERENCES}

Bamgboye EA, Ogunnowo BE, Badru OB, Adewoye EO

(2001). Students admission grades and their performance at the Ibadan University preclinical MBBS examinations. Afr. J. Med \& Med. Sci., 30, 207-211.

Kale, $\mathbf{O . O}$ (2004): An educational system in decline; Lecture 3 of "Nigeria in Distress: A trilogy on the Nation's health status". University Lecture, University of Ibadan, P.83. O’dua Printing and Publishing Company, Ibadan.

Oyebola DDO, Adewoye OE, Iyaniwura JO, Alada ARA, Fasanmade A and Raji Y. (2000). A comparative study of students' performance in pre-clinical physiology when assessed by multiple choice and short essay questions. Afr. J. Med. \& Med. Sci., 29, 201 - 205. 